\title{
Inter-Comparison of ASTER and MODIS Surface Reflectance and Vegetation Index Products for Synergistic Applications to Natural Resource Monitoring
}

\author{
Tomoaki Miura $^{1, *}$, Hiroki Yoshioka ${ }^{2}$, Kayo Fujiwara ${ }^{1}$ and Hirokazu Yamamoto ${ }^{3}$
}

1 Department of Natural Resources and Environmental Management, University of Hawaii at Manoa, 1910 East-West Road, Sherman 101, Honolulu, Hawaii 96822, U.S.A.; E-mails: tomoakim@hawaii.edu; kayof@hawaii.edu.

2 Department of Applied Information Science, Aichi Prefectural University, 1522-3 Ibaragabasama, Kumabari, Nagakute, Aichi 480-1198, Japan; E-mail: yoshioka@ ist.aichi-pu.ac.jp

3 Grid Technology Research Center, National Institute of Advanced Industrial Science and Technology, Central 2, 1-1-1 Umezono, Tsukuba, Ibaraki 305-8568, Japan; E-mail: kathkath@ni.aist.go.jp

* Author to whom correspondence should be addressed.

Received: 31 January 2008 / Accepted: 3 April 2008 / Published: 8 April 2008

\begin{abstract}
Synergistic applications of multi-resolution satellite data have been of a great interest among user communities for the development of an improved and more effective operational monitoring system of natural resources, including vegetation and soil. In this study, we conducted an inter-comparison of two remote sensing products, namely, visible/near-infrared surface reflectances and spectral vegetation indices (VIs), from the high resolution Advanced Thermal Emission and Reflection Radiometer (ASTER) (15 m) and lower resolution Moderate Resolution Imaging Spectroradiometer (MODIS) (250 m $500 \mathrm{~m}$ ) sensors onboard the Terra platform. Our analysis was aimed at understanding the degree of radiometric compatibility between the two sensors' products due to sensor spectral bandpasses and product generation algorithms. Multiple pairs of ASTER and MODIS standard surface reflectance products were obtained at randomly-selected, globally-distributed locations, from which two types of VIs were computed: the normalized difference vegetation index and the enhanced vegetation indices with and without a blue band. Our results showed that these surface reflectance products and the derived VIs compared well between the two sensors at a global scale, but subject to systematic
\end{abstract}


differences, of which magnitudes varied among scene pairs. An independent assessment of the accuracy of ASTER and MODIS standard products, in which "in-house" surface reflectances were obtained using in situ Aeronet atmospheric data for comparison, suggested that the performance of the ASTER atmospheric correction algorithm may be variable, reducing overall quality of its standard reflectance product. Atmospheric aerosols, which were not corrected for in the ASTER algorithm, were found not to impact the quality of the derived reflectances. Further investigation is needed to identify the sources of inconsistent atmospheric correction results associated with the ASTER algorithm, including additional quality assessments of the ASTER and MODIS products with other atmospheric radiative transfer codes.

Keywords: product inter-comparison, surface reflectance, vegetation index, ASTER, MODIS

\section{Introduction}

Numerous studies have demonstrated remote sensing as an effective tool for natural resource inventory/interpretation and environmental monitoring, including forest inventory, rangeland productivity monitoring, mapping deforestation dynamics, and alien species/weed invasion assessments, to name a few [1-4]. In particular, applications of synergistic, multi-resolution remote sensing have been shown to improve remote sensing-based land characterization and monitoring capabilities [5-8], offering great potential for the development of more effective operational monitoring and management decision support systems [9-11]. This has further been facilitated by the advent of satellite programs such as the National Aeronautics and Space Administration (NASA) Earth Observing System (EOS) and European Remote Sensing (ERS) programs as these programs provide systems of coordinated satellite sensors and measurements [12].

One significant achievement by these satellite programs is a provision of "ready-to-use" remote sensing products that have been generated by science-based, calibrated, and validated algorithms [e.g., 13,14]. For example, two sensors onboard the Terra satellite platform, Advanced Spaceborne Thermal Emission and Reflection Radiometer (ASTER) and Moderate Resolution Imaging Spectroradiometer (MODIS), both provide georectified, atmospherically-corrected surface reflectance data as one of their standard products, which require no other basic processing for their application users to perform $[13,14]$.

There exist differences in these ready-to-use, standard products that may need to be addressed for their synergistic applications, namely the sensor characteristics and product generation algorithm differences. The sensor spectral response functions can lead to systematic differences in reflectances and vegetation indices (VIs) $[15,16]$. Differences in the spatial resolutions can also cause systematic differences in VIs since its magnitude changes non-linearly over a range of vegetation cover conditions $[17,18]$. Likewise, systematic differences or inconsistency among the similar products (e.g., VIs, land cover) from different sensors or even from the same sensor can occur when each of the products are generated through, for example, different atmospheric correction algorithms [19-21]. ASTER and 
MODIS are onboard the same Terra platform, which is a significant advantage for their synergistic applications.

There have, however, been few studies that have addressed the compatibility issue between ASTERand MODIS-derived surface reflectances and/or VIs [8]. Using the simple linear regression model of [22], Muukkonen et al. [8] cross-calibrated ASTER and MODIS red and near-infrared (NIR) reflectances for spectral bandpass differences for a boreal forest in Finland with the resultant $\mathrm{R}^{2}$ values of 0.44 and 0.63 for the red and NIR reflectance calibrations, respectively.

In this study, we used a larger and more diverse dataset and evaluated radiometric compatibility of the ASTER and MODIS standard, atmospherically-corrected surface reflectance products and the derived VIs from the products with the goal of obtaining a recommended cross-calibration strategy. We focused our efforts on investigating the impacts of differences in their spectral response functions and atmospheric correction algorithms by means of product inter-comparison, in which the magnitudes of systematic differences between the two products and their geographic and land cover dependencies were examined. We further assessed the quality or accuracy of the standard products by comparing them against an "in-house" surface reflectance and VI dataset that was generated by atmosphericallycorrecting ASTER and MODIS level 1B radiance data using in situ atmospheric data. In the following, we first briefly describe and contrast the sensor characteristics and the atmospheric correction algorithms of ASTER and MODIS (Section 2). This is followed by the description of data analysis methods in Section 3. In Section 4, results of our product inter-comparison analyses and accuracy assessments are presented. A summary of the results, recommendations, and conclusions is given in Section 5.

\section{Comparisons of ASTER and MODIS Sensors and Algorithms}

Launched in December 1999, both ASTER and MODIS are research facility instruments onboard the NASA EOS Terra satellite platform [13,14]. MODIS is designed to provide long-term global observations every 1 to 2 days at moderate spatial resolutions $(250 \mathrm{~m}-1 \mathrm{~km})$ and complemented by the second MODIS on the EOS Aqua platform launched in May 2002 [14]. ASTER, on the other hand, works as the "zoom lens" and provides the highest spatial resolution surface spectral reflectance, temperature, and emissivity data $(15 \mathrm{~m}-60 \mathrm{~m})$ of all the Terra instruments (Table 1) [13]. Although their imaging methods differ (i.e., the ASTER VNIR and SWIR subsystems are push-broom, whereas MODIS and the ASTER TIR subsystem are cross-tack scanning systems; see Table 1), the image acquisition time and, therefore, the sun-target-view geometry of any ASTER and MODIS scene pair is basically identical, an advantageous side effect of the two sensors being on the same platform. The two sensors have achieved a very high level of geolocation accuracy which appears to be at a comparable level to the Terra spacecraft positional accuracy [23-25]. 
Table 1. Selected Instrument Characteristics of the ASTER and MODIS Sensors

\begin{tabular}{lll}
\hline & \multicolumn{1}{c}{ ASTER [13] } & \multicolumn{1}{c}{ MODIS [14] } \\
\hline Swath Width & VNIR $^{\mathrm{a}}$ \& SWIR : 60 km, push-broom & $2,330 \mathrm{~km}$, whisk-broom \\
& TIR $^{\mathrm{a}}: 60 \mathrm{~km}$, cross-track scanning & $\pm 55^{\circ}$ cross-track scanning \\
& $\pm 24^{\circ}$ cross-track pointing for VNIR & \\
& $\pm 8.55^{\circ}$ cross-track pointing for SWIR \& TIR & \\
Spectral Bands & 14 bands, between 0.520 and 11.650 $\mu \mathrm{m}$ & 36 bands, between 0.405 and $14.385 \mu \mathrm{m}$ \\
Spatial & $15 \mathrm{~m}$ (VNIR: bands 1-3) & $250 \mathrm{~m}$ (bands 1-2) \\
Resolutions at & $30 \mathrm{~m}$ (SWIR: bands 4-9) & $500 \mathrm{~m}$ (bands 3-7) \\
Nadir & $60 \mathrm{~m}$ (TIR: bands 10-14) & $1,000 \mathrm{~m}$ (bands 8-36) \\
Radiometric & 8 bits & 12 bits \\
Resolution & & \\
Geolocation & $\pm 50 \mathrm{~m}$ (1 s.d. ${ }^{\mathrm{b}}$ at nadir) [23,24] & $\pm 50 \mathrm{~m}$ (1 s.d. at nadir) [25] \\
Accuracy & & \\
\hline
\end{tabular}


thermal infrared (TIR) subsystems [13].

${ }^{\mathrm{b}}$ Standard deviation.

Compared in Figure 1 are the normalized spectral response curves of the three ASTER visible/nearinfrared (VNIR) and first four MODIS bands that are commonly used in the computation of spectral vegetation indices (VIs). In general, these MODIS bands are much narrower in their bandwidths than the ASTER VNIR bands. Likewise, the red and near-infrared (NIR) bands of the two sensors are not centered around the same wavelengths. Whereas the MODIS red band completely avoids the red edge region $(\sim 680 \mathrm{~nm})$, the ASTER counterpart extends to cover that wavelength range. The MODIS NIR band overlaps at the longest wavelength portion of the ASTER counterpart. These are the consequences of the MODIS band selection requirements to avoid Fraunhofer lines and atmospheric absorption lines and to include key features in target spectra [26] and of the ASTER VNIR bandpasses inherited from those of the Landsat Thematic Mapper and/or the Optical Sensor of the Japanese Earth Resource Satellite (JERS-1) while assuring a provision of good signal-to-noise ratio, high spatial resolution data [13]. It should be noted that the ASTER sensor does not have a blue band.

Both ASTER and MODIS provide atmospherically-corrected, surface reflectance products (AST07 and MOD09, respectively) as one of their standard products. Each of these products incorporates its own atmospheric correction algorithm, which are summarized and compared in Table 2. Details of the ASTER and MODIS atmospheric correction algorithms are found in [28] and [29], respectively. Both algorithms use a combination of pre-computed lookup tables (LUTs) and on-time execution of radiative transfer codes. The two algorithms also require the same four inputs: (1) surface pressure, (2) ozone concentration, (3) column water vapor, and (4) aerosol optical thickness and type. The ASTER algorithm completely relies on outside sources for the required atmospheric information due to the fact that the sensor was not designed to retrieve atmospheric information [28]. This was identified as a key issue and challenge during the algorithm development stage [28]. Although these two algorithms are capable of correcting atmospheric adjacency effects, the modules have not been activated and the current product generations assume an homogeneous, Lambertian surface case [28,30]. 
Figure 1. Normalized spectral response curves of $\operatorname{ASTER} \operatorname{VNIR}(1,2$, and $3 \mathrm{~N})$ and MODIS land (1, 2, 3, and 4) bands (sources: http://asterweb.jpl.nasa.gov/characteristics.asp \& ftp://ftp.mcst.ssai.biz/pub/permanent/MCST/PFM_L1B_LUT_4-30-99/). The “A” and "M" in the parentheses stand for ASTER and MODIS, respectively, and the numbers that follow A or M are the band numbers. Typical reflectance spectra of forest, grassland, and bare soil are also plotted for reference [27].

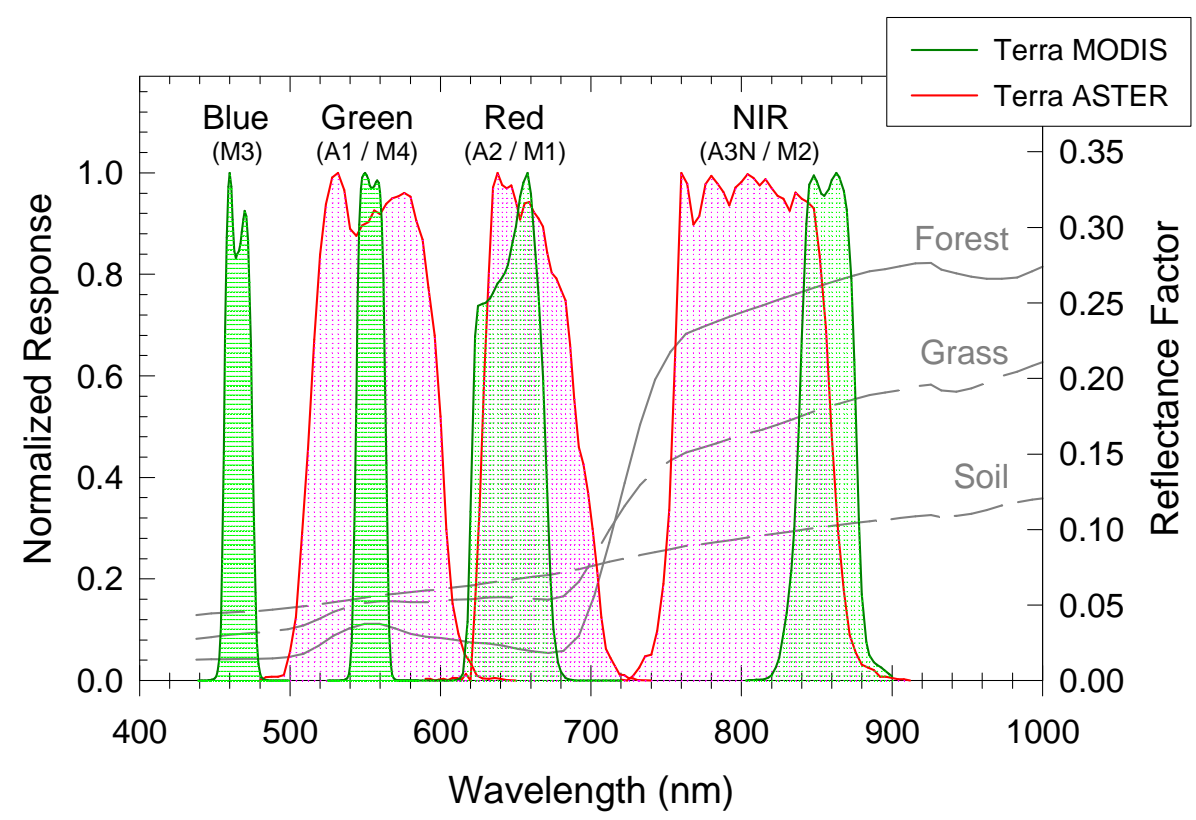

Five major differences can be observed between these two algorithms in Table 2 [28,29]. First, the ASTER and MODIS atmospheric correction algorithms are based on different radiative transfer codes. Second, the amounts of on-time computations are different; the ASTER algorithm computes gaseous transmission terms on-time, whereas the MODIS algorithm computes molecular scattering terms ontime in addition to the gaseous transmission terms. Third, the ASTER algorithm uses interpolation techniques to account for changes in solar zenith (and aerosol optical depth), but uses the LUT nearestcase approach for the molecular scattering optical depth and view angle, whereas the MODIS algorithm always interpolates the LUT for all LUT-retrieved atmospheric terms (aerosol-related). Fourth, the two algorithms use different input data sources for ozone concentration and column water vapor. Finally, the ASTER algorithm does not currently correct for atmospheric aerosol effects (the aerosol optical depth being set to zero) for a lack of any reliable and compatible aerosol data sources for global applications.

Accuracy or uncertainty in the atmospheric correction varies significantly depending on surface reflectance, atmospheric condition, and sun/view geometry. Theoretical uncertainty analyses indicated that overall uncertainty in ASTER surface reflectance is $14 \%$ for a low reflectance case (reflectance < 0.1 ) and $7 \%$ for a high reflectance case (reflectance >0.1) [28], whereas the overall uncertainty of MODIS surface reflectance is estimated as 5-9\% for a clear - high aerosol loading condition [29]. 
Table 2. Correction Approaches and Input and Ancillary Data Sources Used in ASTER and MODIS Atmospheric Correction (Surface Reflectance) Algorithms

\begin{tabular}{|c|c|c|}
\hline & ASTER (AST07) & MODIS (MOD09) \\
\hline PGE $^{\mathrm{a}}$ Version & 3.1 & 4.0 .10 \\
\hline $\begin{array}{l}\text { Radiometric } \\
\text { Calibration }\end{array}$ & $\begin{array}{l}\text { WRC }{ }^{\text {b }} \text { exo-atmospheric solar irradiance } \\
(4 \% \text { calibration accuracy) }[28]\end{array}$ & $\begin{array}{l}\text { Direct computation of } \mathrm{TOA}^{\mathrm{c}} \text { reflectance by } \\
\text { ratioing to the solar diffuser panel readings } \\
(2 \% \text { calibration accuracy) }[31]\end{array}$ \\
\hline \multirow[t]{4}{*}{ Approach } & $\begin{array}{l}\text { Combined LUT }{ }^{\mathrm{d}} \text {-matching and on-time } \\
\text { MODTRAN computation[28]: }\end{array}$ & $\begin{array}{l}\text { Combined LUT-interpolation and on-time } 6 \mathrm{~S} \\
\text { computation[29]: }\end{array}$ \\
\hline & - LUT generated by a Gauss-Seidel & - LUT generated by the $6 \mathrm{~S}$ code[33] \\
\hline & iteration code[32] & - Molecular terms by on-time $6 \mathrm{~S}$ \\
\hline & $\begin{array}{l}\text { - Scattering terms by LUT-matching \& } \\
\text { gaseous transmission terms by } \\
\text { MODTRAN }\end{array}$ & $\begin{array}{l}\text { computation \& aerosol terms by LUT- } \\
\text { interpolation }\end{array}$ \\
\hline Pressure & $\begin{array}{l}\text { NCEP GDAS }{ }^{\mathrm{e}} \text { adjusted for local elevation } \\
\text { using GTOPO } 30^{\mathrm{f}}\end{array}$ & $\begin{array}{l}\text { NCEP GDAS adjusted for local elevation } \\
\text { using GTOPO30 }\end{array}$ \\
\hline Ozone & NCEP TOVS ${ }^{g}$ & NASA TOMS $^{\mathrm{h}}$ \\
\hline Water Vapor & NCEP GDAS & MODIS water vapor[34] \\
\hline Aerosol & No correction & MODIS aerosols \\
\hline Accuracy & $14 \%$ for $\rho<0.1 ; 7 \%$ for $\rho>0.1$ & $5-9 \%$ for clear - high aerosol loadings \\
\hline
\end{tabular}

${ }^{\mathrm{a}}$ Product Generating Executable

${ }^{\mathrm{b}}$ World Radiation Center

${ }^{\mathrm{c}}$ Top-of-Atmosphere

${ }^{\mathrm{d}}$ Lookup Table

${ }^{\mathrm{e}}$ The National Center for Environmental Prediction (NCEP) Global Data Assimilation System (GDAS)

${ }^{\mathrm{f}}$ GTOPO30 (http://edc.usgs.gov/products/elevation/gtopo30/gtopo30.html)

${ }^{\mathrm{g}}$ TIROS (Television Infrared Observation Satellites) Operational Vertical Sounder (TOVS)

${ }^{\mathrm{h}}$ Total Ozone Mapping Spectrometer

\section{Materials and Methods}

\subsection{Intercomparison}

A sample of ASTER and MODIS standard daily atmospherically-corrected surface reflectance products (AST07 and MOD09, respectively) was acquired over the global land area (Figure 2). We first randomly selected 100 locations and then assessed the availability of near-cloud free ASTER scenes in year 2003 at each of these locations. When a near-cloud free ASTER scene was found, the MODIS scene on the same date at the same location was obtained. This first selection resulted in 82 paired scenes at 59 locations. A second screening on the selected scene pairs was performed because some of the scenes that were initially considered free of cloud cover were found to be contaminated with clouds. This second selection resulted in a total of 47 paired scenes at 31 locations (Figure 2). 
Figure 2. Global distribution of ASTER vs. MODIS comparative analysis locations.

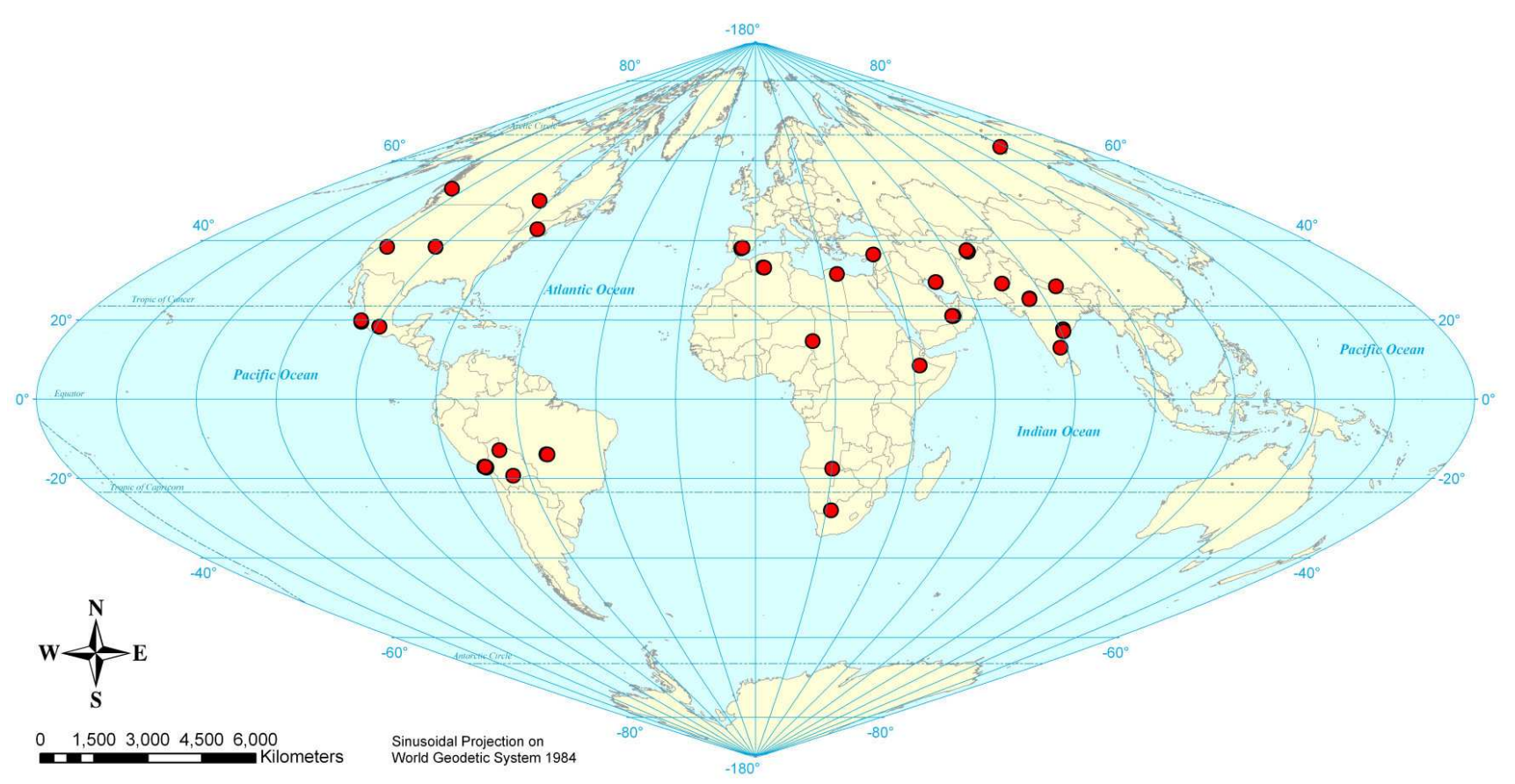

All of the ASTER scenes were reprojected from their original Universal Transverse Mercator (UTM) coordinate system onto a sinusoidal projection used in the MODIS surface reflectance product. A $5 \mathrm{~km}$ square grid was generated for and overlaid on every ASTER and MODIS scene pair. Typically, 130 5-km grid cells were defined on a single ASTER-MODIS pair. Pixels within every $5 \mathrm{~km}$ grid cell were averaged to create one pair of ASTER-MODIS reflectance values, resulting in $~ 130$ pairs of reflectances from one ASTER-MODIS scene pair. We examined several window sizes from $1 \mathrm{~km}-\mathrm{by}-1$ $\mathrm{km}$ to $7 \mathrm{~km}$-by- $7 \mathrm{~km}$ and found that a $5 \mathrm{~km}-\mathrm{by}-5 \mathrm{~km}$ window seemed an optimum size to compensate for mis-registration between ASTER and MODIS scenes.

Three spectral vegetation indices were computed from these matched, aggregated reflectances. The Normalized Difference Vegetation Index (NDVI) was computed as [35]:

$$
N D V I=\frac{\rho_{\text {NIR }}-\rho_{\text {red }}}{\rho_{\text {NIR }}+\rho_{\text {red }}}
$$

where $\rho_{\text {red }}$ and $\rho_{\text {NIR }}$ were the red (ASTER Band 2 or MODIS Band 1) and NIR (ASTER Band 3N or MODIS Band 2) reflectances, respectively. For MODIS, the Enhanced Vegetation Index (EVI), which was developed to optimize the vegetation signal with improved sensitivity in high biomass regions and improved vegetation monitoring through a de-coupling of the canopy background signal and a reduction in atmosphere influences, was also computed [36]:

$$
E V I=2.5 \cdot \frac{\rho_{\text {NIR }}-\rho_{\text {red }}}{\rho_{\text {NIR }}+\left(6 \rho_{\text {red }}-7.5 \rho_{\text {blue }}\right)+1},
$$

where $\rho_{\text {blue }}$ was the blue reflectance (MODIS Band 3) which was to correct for aerosol influences in the index itself [37]. Since the ASTER sensor does not have a blue band, we used a two-band version of 
the EVI (EVI2) to compare against MODIS EVI, which was developed and being used as a backup algorithm in the MODIS VI algorithm[38]:

$$
E V I 2=2.4 \cdot \frac{\rho_{N I R}-\rho_{\text {red }}}{\rho_{\text {NIR }}+\rho_{\text {red }}+1} .
$$

Although its compatibility with the three-band EVI has been thoroughly examined and verified, we expected some incompatibility of the ASTER-based EVI2 against the MODIS-derived EVI as the former's coefficients were adjusted for MODIS band passes.

We first compared these aggregated reflectances, NDVI, and EVI/EVI2 from all the scene pairs at once to examine an overall trend and compatibility between ASTER and MODIS. Mean differences (MDs) between the ASTER and MODIS radiometric variables, along with standard deviations of the differences (SDs) and of the mean differences (or standard errors, SEs), were computed as a quantitative measure of discrepancies:

$$
\begin{gathered}
M D=\frac{1}{n} \sum_{i=1}^{n}\left(x_{i, A S T E R}-x_{i, M O D I S}\right), \\
S D=\sqrt{\frac{1}{n-1} \sum_{i=1}^{n}\left[\left(x_{i, A S T E R}-x_{i, M O D I S}\right)-M D\right]^{2}}, \\
S E=\frac{S D}{\sqrt{n}},
\end{gathered}
$$

where $x_{i, A S T E R}$ and $x_{i, M O D I S}$ are the reflectance or VI values of ASTER and MODIS, respectively, for the $5-\mathrm{km}$ square grid cell $i$, and $n$ is the sample size (the number of pairs). Although these SD and SE estimates were likely to underestimate the true variations due to spatial autocorrelation, these were used to establish 99\% confidence intervals. This comparative analysis was made for the two reflectances that were used for the computations of VIs and that both the sensors had (i.e., red and NIR), between ASTER and MODIS NDVI and between ASTER EVI2 and MODIS EVI.

We then repeated the same comparative analysis, but stratified the results by land cover. The 2001 International Geosphere-Biosphere Programme (IGBP) land cover type information from the Terra MODIS standard, $1 \mathrm{~km}$ yearly land cover product (MOD12Q1) was obtained for the areas covered by each of the ASTER-MODIS scene pairs. The 17 IGBP land cover classes were lumped into a smaller number of categories, including forest, shrubland, savanna, grassland, cropland, and barren.

Finally, seasonal dependencies of ASTER and MODIS differences were examined using a desert site. A desert site devoid of vegetation was considered ideal for this purpose because this type of land is usually not subject to frequent cloud cover, it does not exhibit seasonality associated with vegetation growth, there is a low concentration of and variability in atmospheric water vapor, and it is used for long-term stability monitoring of satellite sensors. Six pairs of cloud-free ASTER/MODIS scenes from the year $2003(1 / 27,2 / 12,3 / 5,3 / 16,5 / 19$, and 6/20) were located and obtained from a desert sand dune area in Saudi Arabia. These six scene pairs were overlaid and aggregated reflectance and VI values were extracted from them. MD and SD, along with means and standard deviations, of the aggregated reflectances and VIs were computed on a per-scene-pair (per-date) basis and plotted against acquisition date for a trend analysis. 


\subsection{Accuracy Assessment}

Product inter-comparison could only allow for the examination of consistency (or relative differences) among similar products. Thus, we conducted another independent experiment to examine/investigate accuracy or "overall quality" of ASTER and MODIS surface reflectance products and VIs by comparing the standard products against "in-house" products.

Six locations within the conterminous USA were selected based upon a diversity of land cover types, availabilities of nearly cloud-free ASTER scenes, and availabilities of in situ atmospheric measurements from the Aerosol Robotic Network (AERONET) [39] (Table 3). Radiometricallycalibrated ASTER and MODIS Level 1B products (AST_L1B and MOD02) as well as MODIS geolocation angle products (MOD03) were obtained for the selected sites and dates listed in Table 3 and reprojected onto the UTM coordinate system. On each of the 14 paired scenes, ten $5 \mathrm{~km}-\mathrm{by}-5 \mathrm{~km}$ grids were located near the AERONET sunphotometer locations and all the pixels within each grid cell were extracted and averaged.

Table 3. List of Study Sites and In Situ Atmospheric Properties Used for ASTER vs. MODIS Accuracy Assessments

\begin{tabular}{|c|c|c|c|c|c|c|c|}
\hline Site Name & Biome Type & $\begin{array}{c}\text { Date } \\
\left(\text { DOY }^{\mathrm{a}}\right)\end{array}$ & $\begin{array}{l}\text { Solar } \\
\text { Zenith }\end{array}$ & $\begin{array}{l}\text { View } \\
\text { Zenith }\end{array}$ & $\begin{array}{l}\text { *Ozone } \\
\text { (Dobson) }\end{array}$ & $\begin{array}{c}{ }^{* W . V .}{ }^{b} \\
(\mathbf{c m}- \\
\text { atm) }\end{array}$ & $\begin{array}{c}{ }^{*} \mathrm{AOT}^{\mathrm{c}} \\
(\mathbf{5 5 0} \mathrm{nm})\end{array}$ \\
\hline HJ Andrews, OR & Needleleaf Forest & $09 / 24(267)$ & $46^{\circ}$ & $5^{\circ}$ & 284 & 1.0 & .04 \\
\hline Bondville, IL & Broadleaf Cropland & $\begin{array}{l}03 / 06(065) \\
09 / 07(250)\end{array}$ & $\begin{array}{l}48^{\circ} \\
37^{\circ}\end{array}$ & $\begin{array}{l}3^{\circ} \\
7^{\circ}\end{array}$ & $\begin{array}{l}348 \\
280\end{array}$ & $\begin{array}{l}0.8 \\
2.1\end{array}$ & $\begin{array}{l}.15 \\
.14\end{array}$ \\
\hline Maricopa, AZ & Broadleaf Cropland & $\begin{array}{l}01 / 12(012) \\
08 / 24(236) \\
09 / 16(259)\end{array}$ & $\begin{array}{l}58^{\circ} \\
28^{\circ} \\
34^{\circ}\end{array}$ & $\begin{array}{l}8^{\circ} \\
8^{\circ} \\
5^{\circ}\end{array}$ & $\begin{array}{l}297 \\
287 \\
288\end{array}$ & $\begin{array}{l}1.7 \\
0.9 \\
0.7\end{array}$ & $\begin{array}{l}.10 \\
.02 \\
.10\end{array}$ \\
\hline Konza Prairie, KS & $\begin{array}{l}\text { Prairie Grassland } \\
\& \text { Cereal Crop }\end{array}$ & $\begin{array}{l}06 / 06(157) \\
11 / 20(324)\end{array}$ & $\begin{array}{l}22^{\circ} \\
60^{\circ}\end{array}$ & $\begin{array}{r}10^{\circ} \\
1^{\circ}\end{array}$ & $\begin{array}{l}324 \\
288\end{array}$ & $\begin{array}{l}1.9 \\
1.0\end{array}$ & $\begin{array}{l}.08 \\
.01\end{array}$ \\
\hline Sevilleta, NM & $\begin{array}{l}\text { Semi-arid Grassland } \\
\& \text { Cereal Crop }\end{array}$ & $\begin{array}{l}04 / 20(110) \\
05 / 06(126) \\
06 / 16(167) \\
07 / 02(183)\end{array}$ & $\begin{array}{l}27^{\circ} \\
22^{\circ} \\
19^{\circ} \\
20^{\circ}\end{array}$ & $\begin{array}{l}6^{\circ} \\
6^{\circ} \\
6^{\circ} \\
6^{\circ}\end{array}$ & $\begin{array}{l}321 \\
320 \\
304 \\
300\end{array}$ & $\begin{array}{l}0.4 \\
0.3 \\
1.0 \\
1.0\end{array}$ & $\begin{array}{l}.08 \\
.08 \\
.15 \\
.48\end{array}$ \\
\hline Railroad Valley, NV & Desert Scrub & $\begin{array}{l}08 / 20(232) \\
09 / 21(264)\end{array}$ & $\begin{array}{l}30^{\circ} \\
40^{\circ}\end{array}$ & $\begin{array}{l}2^{\circ} \\
2^{\circ}\end{array}$ & $\begin{array}{l}290 \\
281\end{array}$ & $\begin{array}{l}0.5 \\
0.7\end{array}$ & $\begin{array}{l}.07 \\
.01\end{array}$ \\
\hline
\end{tabular}

${ }^{*}$ The values in these columns were obtained from the Aerosol Robotic Network (AERONET) website (http://aeronet.gsfc.nasa.gov/)[39].

${ }^{\mathrm{a}}$ Day of year

${ }^{\mathrm{b}}$ Atmospheric water vapor

${ }^{\mathrm{c}}$ Aerosol optical thickness

The 6S radiative transfer code [30] was constrained with in situ AERONET atmospheric parameters, and solar zenith, view zenith, and relative azimuth angles, and elevations extracted from the corresponding MOD03 products, and run to perform atmospheric corrections on both ASTER and 
MODIS Level 1B products. We performed total atmospheric corrections and atmospheric corrections without aerosols [i.e., by setting aerosol optical thickness (AOT) to zero] on the ASTER Level 1B data, whereas only total atmospheric corrections were performed on the MODIS Level 1B data. Since AOT values were very small except for the July 2 Sevilleta scenes, the continental aerosol model was used for all the aerosol corrections. We did not take into account the coupled atmosphere-surface directional effects or adjacency effects as they were not implemented in the atmospheric corrections of the ASTER and MODIS standard products used in our product inter-comparison analysis. The same VIs as in the above analysis were computed from these reflectances.

Using this dataset, comparisons were made for the following 3 cases:

1) cross-comparison between ASTER standard and in-house (no aerosol correction) products,

2) cross-comparison between ASTER in-house products with and without aerosol correction,

3) cross-comparison between MODIS standard and in-house products.

Cases 1 and 3 were to evaluate the accuracy or quality of ASTER and MODIS standard products, whereas Case 2 was examined for assessing the potential impact of the no aerosol correction scheme implemented in the current ASTER atmospheric correction algorithm. In addition to red and NIR reflectances, we analyzed green reflectance since this spectral band is located at a shorter wavelength region (see Figure 1) and thus likely more sensitive to the quality of atmospheric correction.

\section{Results}

\subsection{Intercomparison}

In Figure 3, red and NIR reflectances, NDVI, and EVI2 of ASTER (AST07) are plotted against the corresponding variables of MODIS (MOD09). All four radiometric variables examined here had nearlinear relationships. Apparent, slight curvelinearity was observed only for the NDVI-to-NDVI relationship (Figure 3c). Both red and NIR reflectances of ASTER were consistently higher than those of MODIS with mean differences (MD) of .027 and .032, respectively (Figure 3a,b). On the other hand, the ASTER NDVI was consistently lower than the MODIS counterpart (MD of -.031) (Figure 3c). The ASTER EVI2 and MODIS EVI scattered about a 1:1 line and had the smallest mean difference of .012 (Figure 3d). From the data continuity perspective, the ASTER and MODIS variables, particularly the NDVI and EVI2/EVI, also had fairly large scatter (Figure 3). The standard deviations of differences were about half the magnitude of the mean differences for red and NIR reflectances (.014 and .017), whereas they were even 1.5 and 2 times larger than the mean differences for the NDVI (.048) and EVI2/EVI (.023), respectively.

In order to assess the large scatter observed in Figure 3, we randomly selected four scenes and plotted differences of ASTER and MODIS reflectances/vegetation indices against the latter. Scene-toscene variability of these differences (relationships between ASTER and MODIS variables) were large (Figure 4). Red reflectance differences were nearly constant throughout its dynamic range for each scene, but their magnitudes differed significantly among them (Figure 4a). NIR reflectance differences also differed among scenes (Figure 4b). One dataset from Spain (the light green triangles in Figure 4b) had large scatter and differences were smaller in general, whereas another dataset from India (the red squares in Figure 4b) had slightly larger differences than the others. 
Figure 3. Scatterplots of ASTER vs. MODIS surface reflectance and vegetation indices: (a) red reflectance, (b) NIR reflectance, (c) NDVI, and (d) EVI2 vs. EVI. MDs in the plots stand for mean differences and the values in the parentheses were standard deviations of the differences.
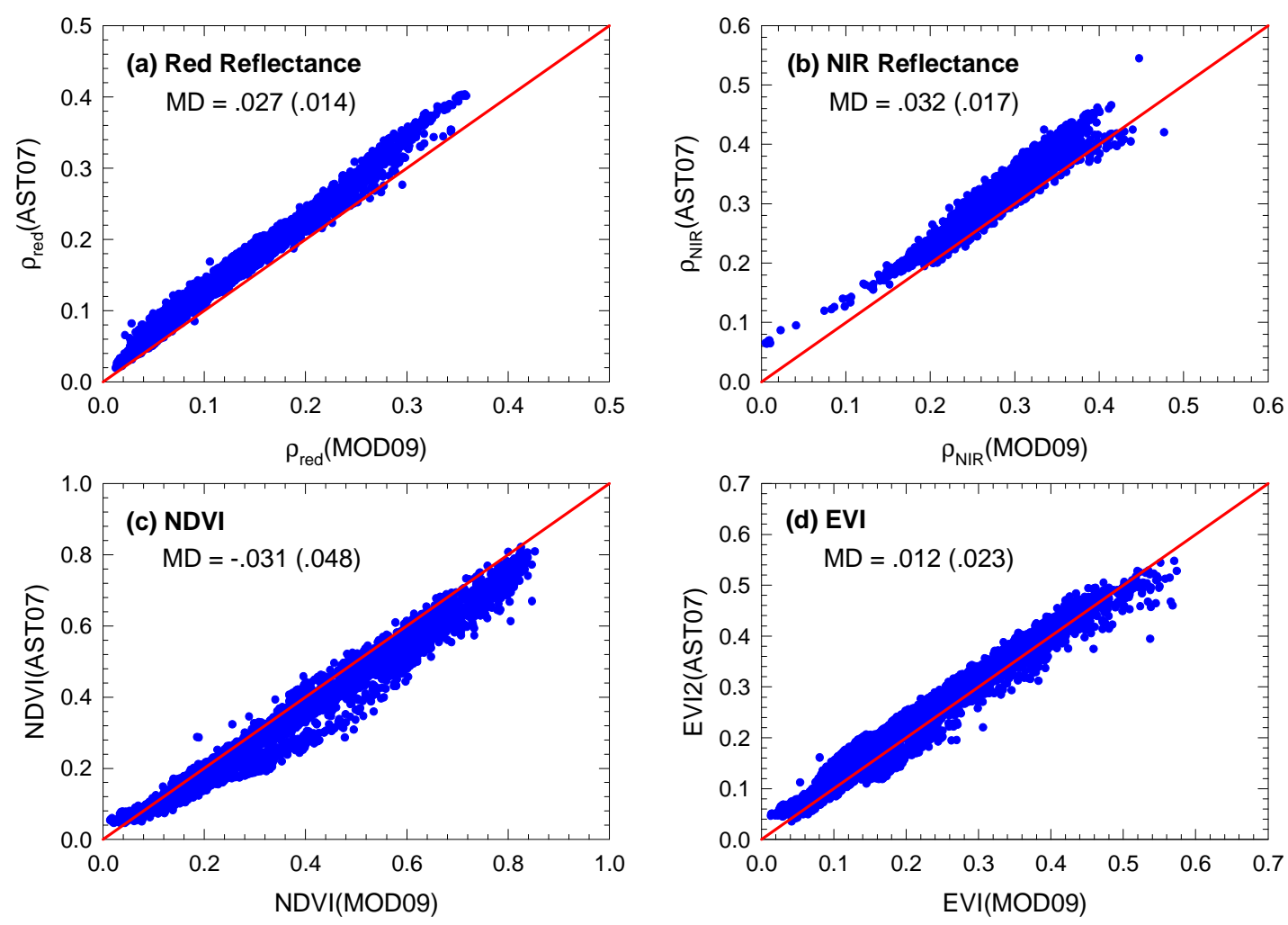

NDVI and EVI2/EVI differences also differed largely among the scenes. For the NDVI, differences for the India scene and one Spain scene had the same magnitudes and convex trends (the red squares and light green triangles in Figure 4c). NDVI differences for the other Spain dataset had the same magnitude and convex trend as the above two datasets; however, they formed a separate relationship since their NDVI values were higher (the yellow triangles in Figure 4c). The Bolivia dataset showed a completely different trend in that its NDVI differences were larger and had a concave trend, having yet another relationship (the black circles in Figure 4c). EVI differences of these four scenes had the same trends, but their magnitudes were much smaller than those of NDVI differences (Figure 4d).

In Figure 5, ASTER vs. MODIS differences (AST07 minus MOD09) are summarized by land cover types. Some land cover dependencies existed in all of the four radiometric variables. NIR reflectance differences were, however, nearly at the same level of .03 except for the barren cover type (Figure $5 b)$. For red reflectance, MD was the largest for barren and the second largest for grassland (Figure 5a). For the NDVI, it was large not only for grassland, but for forest as well (Figure 5c). For the EVI2/EVI, MD was the largest for barren followed by cropland and grassland, but it was positive for the cropland and negative for the grassland (Figure 5d). Smaller MD appeared to be associated with the savanna land cover type for which red and NIR reflectance differences and EVI2/EVI difference were the smallest (Figure 5a,c,d). Although these observations can be made, land cover dependencies of differences did not appear to be consistent across the four radiometric variables. 
Figure 4. Differences of ASTER and MODIS reflectances and vegetation indices (AST07 minus MOD09) plotted against MODIS values.
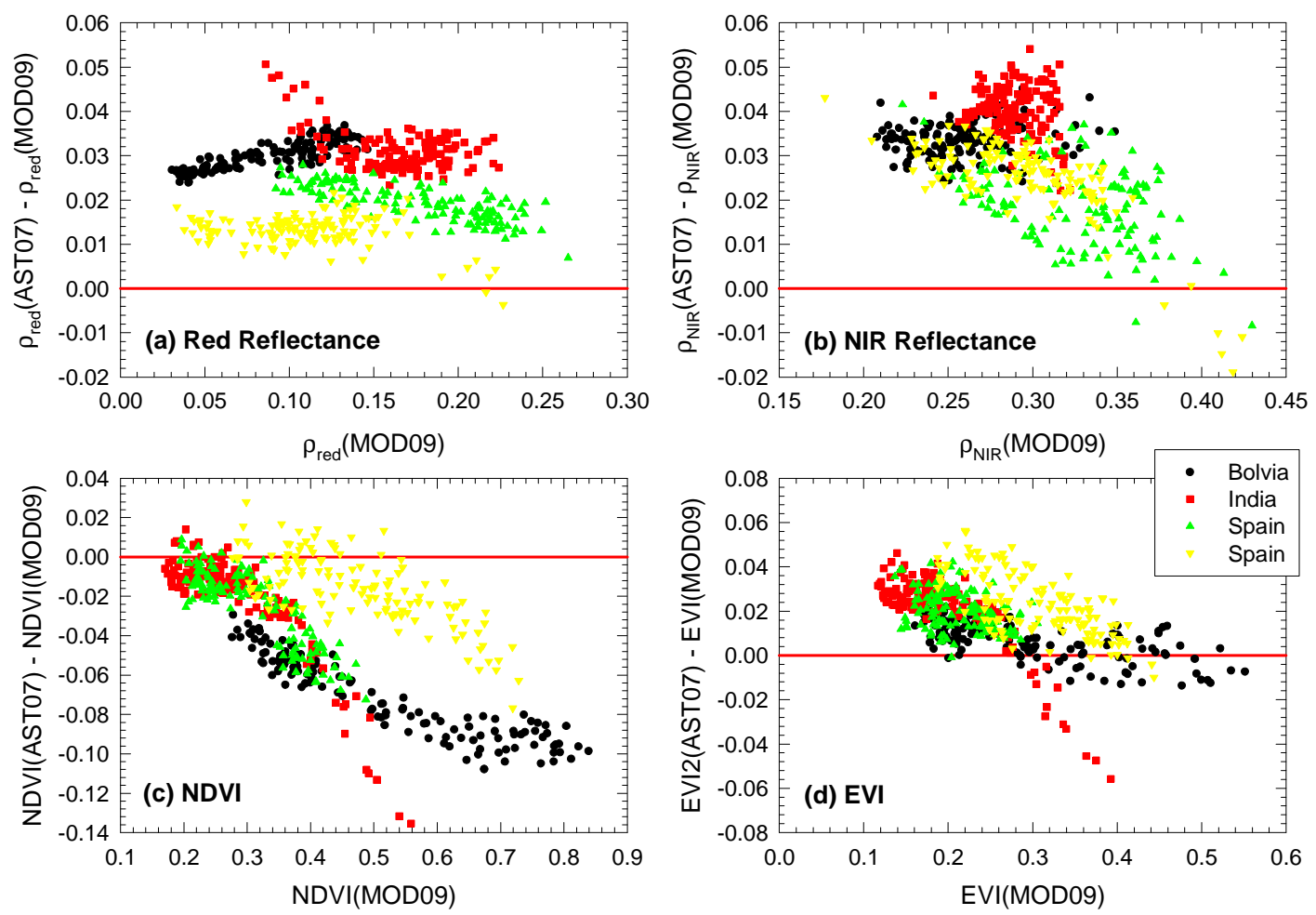

Figure 5. Land cover dependencies of ASTER vs. MODIS differences (AST07 minus MOD09). Per-land cover mean differences are plotted along with $99 \%$ confidence intervals. The sample sizes (number of pairs) used to compute the mean differences and confidence intervals are given at the tops of the bars in (a).
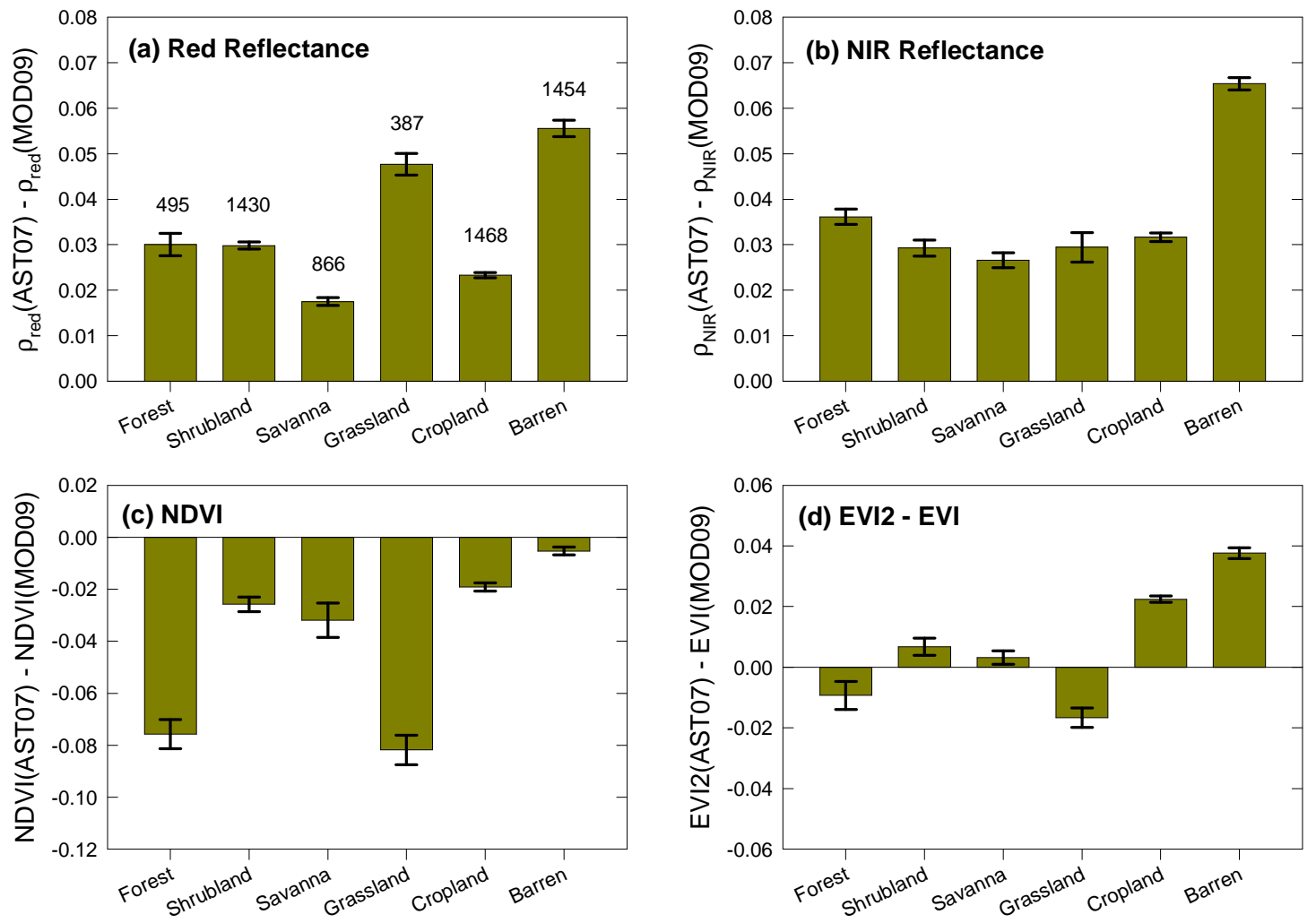
Time series plots of the ASTER and MODIS four radiometric variables and their differences from the desert site are shown in Figure 6. ASTER values were generally higher and exhibited more shortterm variations (no systematic trend) than those of MODIS (Figure 6). While MODIS red and NIR reflectances changed, the changes were rather monotonic with their values first increasing gradually and then decreasing (Figure 6a,b, top). MODIS NDVI changed very little and MODIS EVI remained the same (Figure 6c,d, top). ASTER vs. MODIS mean differences (AST07 minus MOD09) were also highly variable and did not show a strong systematic trend with respect to time (Figure 6). Red reflectance differences had the largest variability, ranging from .02 to .08 (Figure 6a, bottom). Overall, differences between ASTER and MODIS products can not be considered temporal-dependent.

Figure 6. Temporal variability in ASTER (AST07) and MODIS (MOD09) radiometric variables and their differences: (a) red reflectance, (b) NIR reflectance, (c) NDVI, and (d) EVI2 (ASTER) and EVI (MODIS). The bars in the figure correspond to the standard deviation estimates. The sample size was 134 for every scene pair.

(a) Red Reflectance

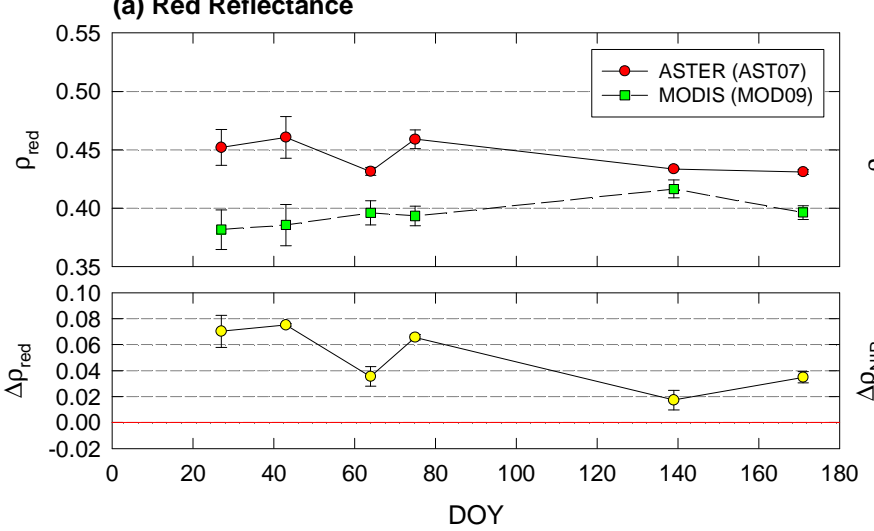

(c) NDVI



(b) NIR Reflectance

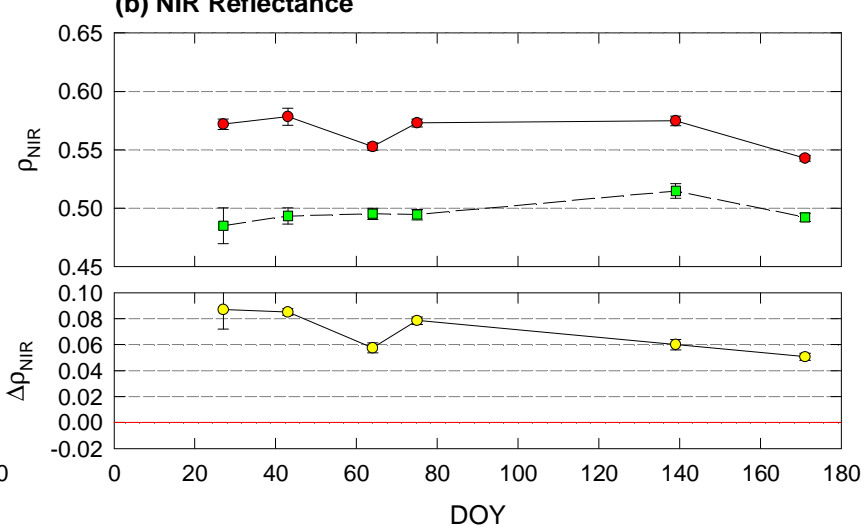

(d) EVI or EVI2

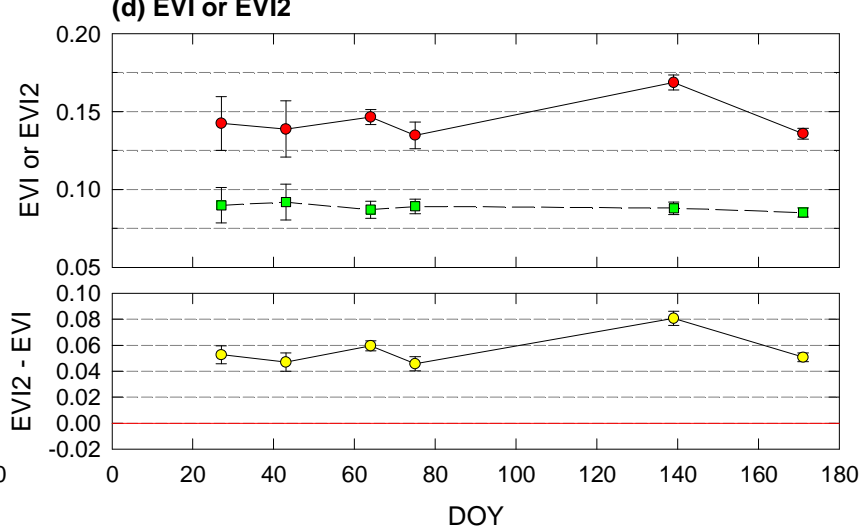

\subsection{Accuracy Assessment}

In Figure 7, reflectances and VIs from the ASTER standard atmospherically-corrected product (AST07) are compared against those that were atmospherically-corrected with in situ Aeronet data ("in-house"). As described in the materials and methods section, we also analyzed green reflectance since the spectral band is located at a shorter wavelength region (see Figure 1) and thus likely more sensitive to quality of atmospheric correction. AST07 reflectance and VI values were basically larger than in-house atmospheric correction results. For the reflectances, discrepancies were the largest for green reflectance followed by NIR and red reflectances (Figure 7a,b,c). AST07 and in-house red 
reflectances were nearly the same at the low values $(0.0-0.1)$, but their differences and variations were larger at higher values (>0.1) (Figure 7b). Both the NDVI and EVI2 from AST07 were larger than the in-house counterparts, but they were about the same values at the lower ranges $(0.0-0.25)$ (Figure 7d,e).

Figure 7. Scatterplots of AST07 vs. atmospherically-corrected ASTER data using in situ Aeronet data for (a) green, (b) red, and (c) NIR reflectances, and (d) NDVI and (e) EVI2. These "in-house" atmospheric corrections of ASTER data were performed by setting aerosol optical thickness to zero, simulating the actual ASTER atmospheric correction scenario.
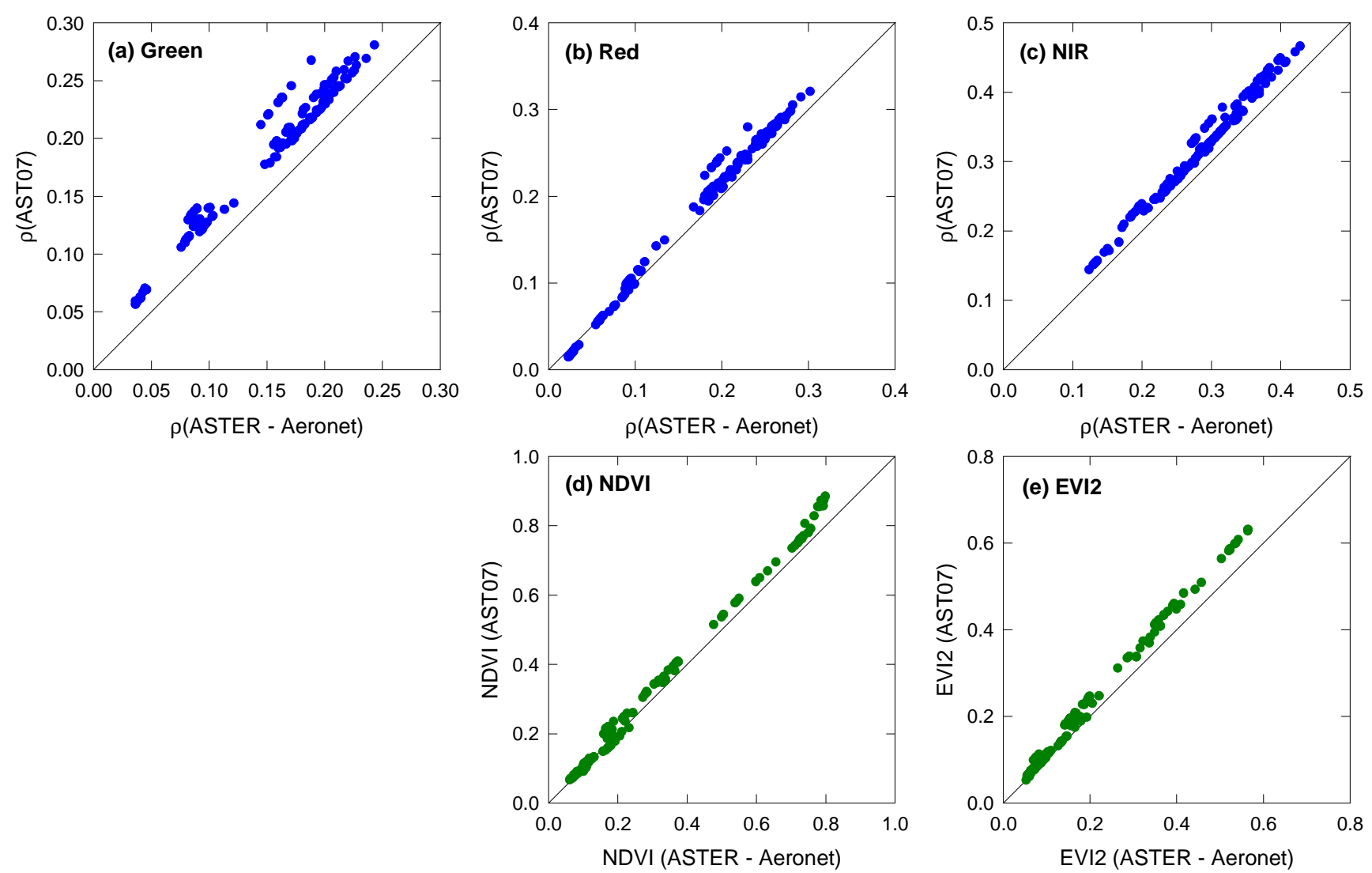

Noticeable deviations from the 1:1 line occurred in the scatterplots, which was particularly clear in the reflectance scatterplots and the most significant in green reflectance (Figure 7). In these plots, one can see several lines (relationships) being formed, each of which was basically from one scene. This indicates that the performance of the ASTER atmospheric correction is variable and inconsistent among scenes. These differences were likely induced by the differences in the atmospheric radiative transfer (RT) codes. Further investigations will be needed to assess the impacts of RT model and ancillary data on accuracy of retrieved surface reflectance.

In Figure 8, in-house atmospheric correction results with and without aerosol corrections are compared. All three reflectances and two VIs from these two correction results (aerosol vs. no aerosol corrections) were extremely comparable, forming near 1:1 relationships with very little scatter (Figure 8). There were several points that slightly deviated from the 1:1 lines for the red and NIR reflectances (Figure 8b,c). These points were, however, from the July 2 Sevilleta scene of which AOT was 
significantly higher (0.48) than those of the other scenes (see Table 3). Not correcting for aerosols should have some impacts on the accuracy of AST07 reflectance and VI products; however, the magnitude of differences and variations observed in Figure 7 were not due to aerosols based on the present results.

Figure 8. Scatterplots of atmospherically-corrected ASTER data using in situ Aeronet data: no aerosol correction vs. aerosol correction.
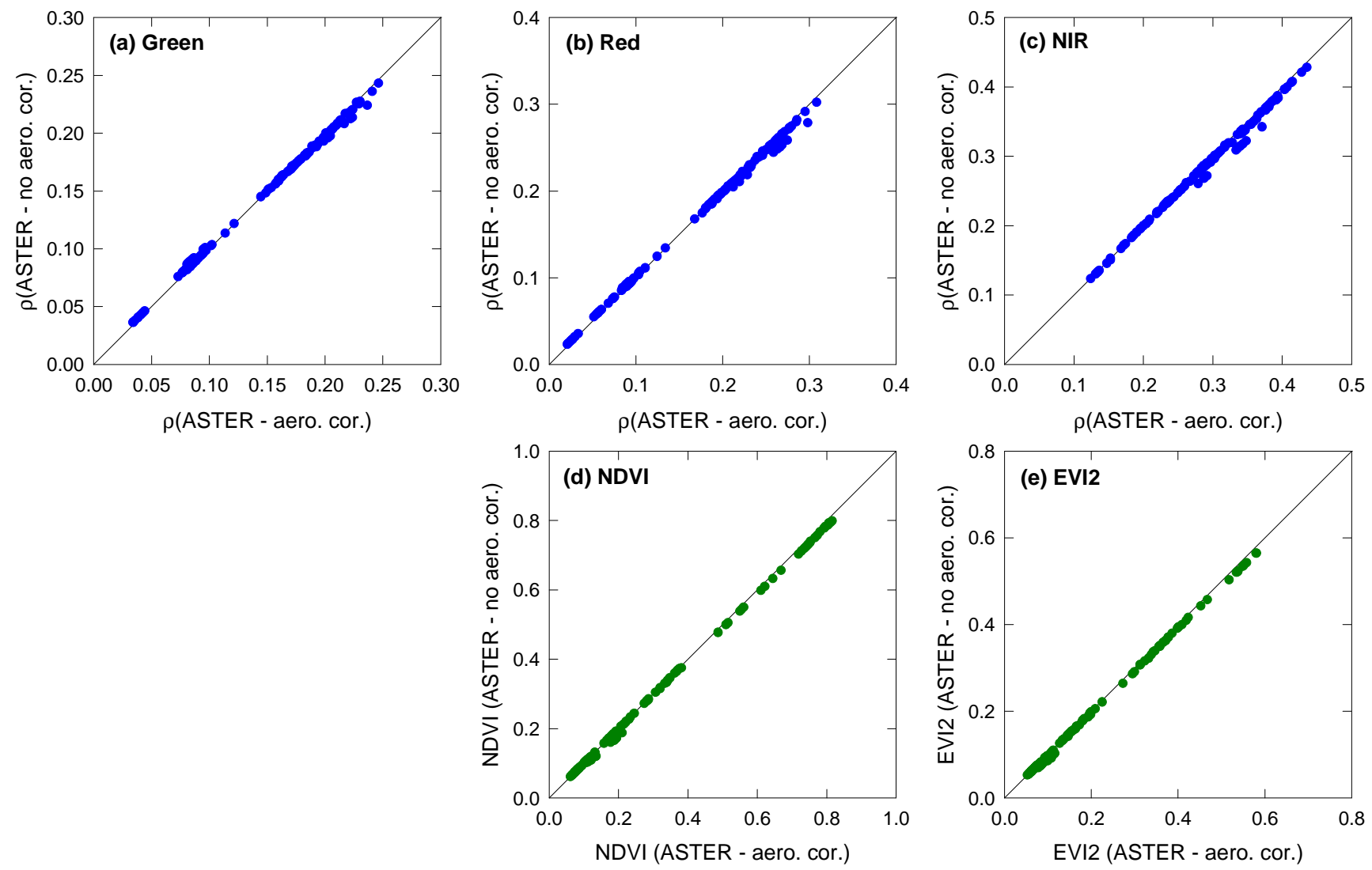

MOD09 reflectances and VIs are plotted against in-house, atmospherically-corrected MODIS data using in situ Aeronet data in Figure 9. These MOD09 and in-house values compared with each other very well, scattering about 1:1 lines only with small variations (without any among-scene variability). This indicates that MOD09 atmospherically-corrected reflectances and VIs can be considered consistent and accurate.

We summarized these differences into mean differences (MDs) (Figure 10). AST07 reflectances and VIs were consistently and significantly higher than those derived using in situ Aeronet data (Figure 10a). MDs were largest for the green and NIR reflectances, whereas it was smallest for red reflectance. Comparisons of these MDs against those due to aerosols clearly indicated that aerosols were not the main factor for causing these large errors in AST07 reflectances and VIs (Figure 10c). On the other hand, the MDs between MOD09 and in-house atmospherically-corrected reflectance/VIs were smaller than those for AST07 vs. its in-house counterparts (Figure 10b). The MD for EVI was slightly larger than all the other radiometric variables, yet smaller than -0.01 (Figure 10b). 
Figure 9. Scatterplots of MOD09 vs. atmospherically-corrected MODIS data using in situ Aeronet data for (a) green, (b) red, and (c) NIR reflectances, and (d) NDVI and (e) EVI.
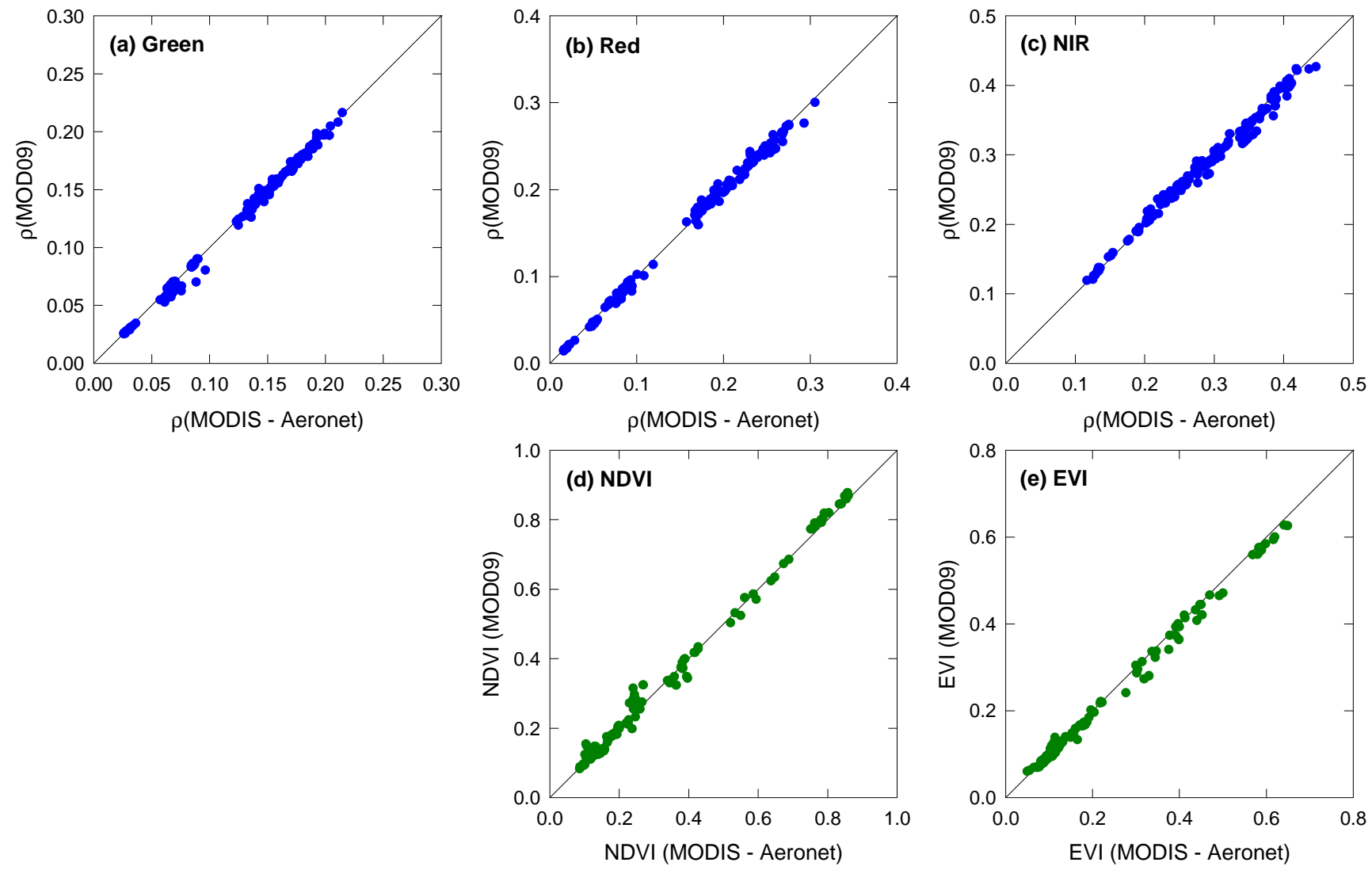

Figure 10. Comparisons of mean differences between official and in-house products: (a) AST07 vs. in-house ASTER, (b) MOD09 vs. in-house MODIS, and (c) ASTER no aerosol vs. aerosol corrections. The error bars in the figure correspond to $99 \%$ confidence intervals. The sample size was 140 .

(a) ASTER
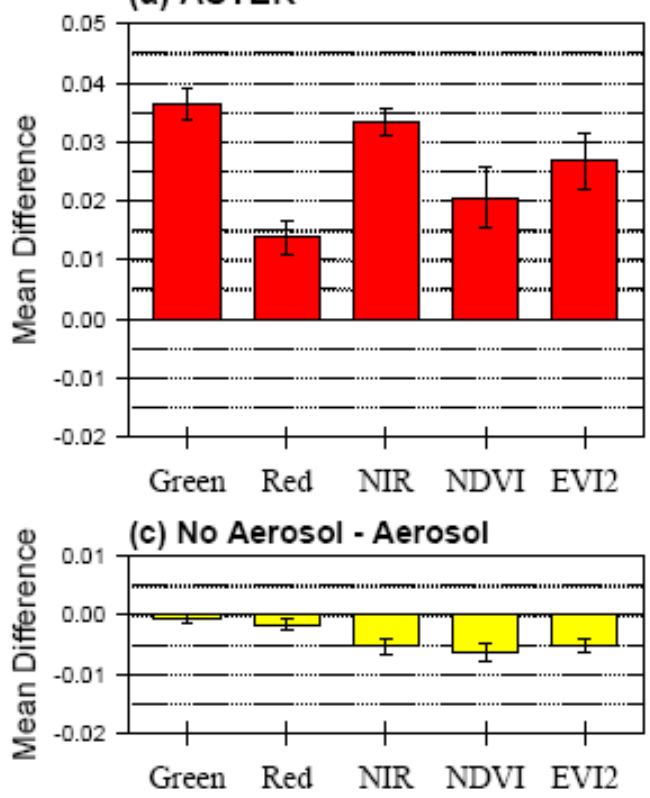

(b) MODIS






\section{Summary and Conclusions}

In this study, we investigated product inter-compatibility between ASTER and MODIS atmospherically-corrected reflectance products (AST07 and MOD09, respectively) and VIs computed from these standard reflectance products. Our analyses showed that surface reflectances and VIs from the two sensors compared well at a global scale. However, they were subject to systematic differences; ASTER reflectance values were higher than those of MODIS and ASTER NDVI values were lower than the MODIS counterparts, whereas ASTER EVI2 values were only slightly higher than MODIS EVI values. Our results also showed that reflectance and VI relationships between AST07 and MOD09 and the magnitude of their systematic differences varied among scene pairs. When a single pair of AST07 and MOD09 scenes were compared, their reflectances and VIs formed good relationships. On the other hand, when multiple pairs were compared together, the slopes and curvelinearity of relationships varied from scene to scene. This inconsistency among scene pairs did not show strong geographic, land cover, or temporal dependencies. Thus, these results indicate that, when ASTER and MODIS reflectance products or VIs are to be cross-calibrated, it needs to be performed on a per-scenepair (local scale) basis for precise and accurate cross-calibration results.

The quality or accuracy assessment results of ASTER and MODIS standard products suggested that the performance of the ASTER atmospheric correction algorithm was not as good as that of MODIS, and that, overall, ASTER surface reflectances and VIs were overestimated based on the dataset and atmospheric radiative transfer code used in this accuracy assessment. However, the assessment results indicated that, although aerosol correction was not implemented in the ASTER atmospheric correction algorithm, this had a minimum impact on quality or accuracy of the derived ASTER surface reflectances and VIs.

Further investigation is needed to identify potential sources of inconsistent atmospheric correction results associated with the ASTER algorithm. These include input atmospheric data sources and the nearest approach used in the LUT search. Accuracy assessments of both the ASTER and MODIS surface reflectance products should also be performed using other atmospheric radiative transfer codes.

\section{Acknowledgements}

The authors would like to thank Kurt Thome for his valuable comments and discussions made while this research was being conducted. The authors would also like to thank Joshua Turner and Yukino Tanaka for their assistance in assembling the datasets used in this study. We thank the PIs of the six Aeronet sites used in this study for their effort in establishing and maintaining these sites. This work was supported by a NASA EOS grant NNG04GL88G.

\section{References}

1. McRoberts, R.E.; Tomppo, E.O. Remote sensing support for national forest inventories. Remote Sens. Environ. 2007, 110(4), 412-419.

2. Marsett, R.C.; Qi, J.G.; Heilman, P.; Biedenbender, S.H.; Watson, M.C.; Amer, S.; Weltz, M.; Goodrich, D.; Marsett, R. Remote sensing for grassland management in the arid Southwest. Rangeland Ecol. Manage. 2006, 59(5), 530-540. 
3. Morton, D.C.; DeFries, R.S.; Shimabukuro, Y.E.; Anderson, L.O.; Espirito-Santo, F.D.B.; Hansen, M.; Carroll, M. Rapid assessment of annual deforestaion in the Brazilian Amazon using MODIS data. Earth Interact. 2005, 9(8), DOI:10.1175/EI139.1.

4. Morisette, J.T.; Jarnevich, C.S.; Ullah, A.; Cai, W.J.; Pedelty, J.A.; Gentle, J.E.; Stohlgren, T. J.; Schnase, J.L. A tamarisk habitat suitability map for the continental United States. Front. Ecol. Environ. 2006, 4(1), 11-17.

5. Hill, M.J.; Held, A.A.; Leuning, R.; Coops, N.C.; Hughes, D.; Cleugh, H.A. MODIS spectral signals at a flux tower site: Relationships with high-resolution data, and $\mathrm{CO} 2$ flux and light use efficiency measurements. Remote Sens. Environ. 2006, 103(3), 351-368.

6. Pu, R.L.; Gong, P.; Michishita, R.; Sasagawa, T. Assessment of multi-resolution and multisensor data for urban surface temperature retrieval. Remote Sens. Environ. 2006, 104(2), 211225.

7. Jacob, F.; Petitcolin, F.; Schmugge, T.; Vermote, E.; French, A.; Ogawa, K. Comparison of land surface emissivity and radiometric temperature derived from MODIS and ASTER sensors. Remote Sens. Environ. 2004, 90(2), 137-152.

8. Muukkonen, P.; Heiskanen, J. Biomass estimation over a large area based on standwise forest inventory data and ASTER and MODIS satellite data: A possibility to verify carbon inventories. Remote Sens. Environ. 2007, 107(4), 617-624.

9. DeFries, R.; Achard, F.; Brown, S.; Herold, M.; Murdiyarso, D.; Schlamadinger, B.; de Souza, C. Earth observations for estimating greenhouse gas emissions from deforestation in developing countries. Environ. Sci. Policy 2007, 10(4), 385-394.

10. Brack, C.L. National forest inventories and biodiversity monitoring in Australia. Plant Biosyst. 2007, 141(1), 104-112.

11. Duro, D.; Coops, N.C.; Wulder, M.A.; Han, T. Development of a large area biodiversity monitoring system driven by remote sensing. Prog. Phys. Geog. 2007, 31(3), 235-260.

12. NRC. Earth Science and Applications from Space: National Imperatives for the Next Decade and Beyond: The National Academies Press, Washington, D.C.; 2007. 428 p.

13. Yamaguchi, Y.; Kahle, A.B.; Tsu, H.; Kawakami, T.; Pniel, M. Overview of Advanced Spaceborne Thermal Emission and Reflection Radiometer (ASTER). IEEE Trans. Geosci. Remote Sensing 1998, 36(4), 1062-1071.

14. Justice, C.O.; Townshend, J.R.G.; Vermote, E.F.; Masuoka, E.; Wolfe, R.E.; Saleous, N.; Roy, D.P.; Morisette, J.T. An overview of MODIS Land data processing and product status. Remote Sens. Environ. 2002, 83(1-2), 3-15.

15. Trishchenko, A.P.; Cihlar, J.; Li, Z. Effects of spectral response function on surface reflectance and NDVI measured with moderate resolution satellite sensors. Remote Sens. Environ. 2002, 81(1), 1-18.

16. Miura, T.; Huete, A.R.; Ferreira, L.G.; Sano, E.E.; Yoshioka, H. A technique for reflectance calibration of airborne hyperspectral spectrometer data using a broad, multi-band radiometer. In: Kalacska M, editor. Hyperspectral Remote Sensing of Tropical and Sub-tropical Forests: CRS Press (in press); 2007. p 218-232. 
17. Price, J.C. Combining multispectral data of differing spatial resolution. IEEE Trans. Geosci. Remote Sensing 1999, 37(3), 1199-1203.

18. Hu, Z.L.; Islam, S. Scale invariant remote sensing algorithms. IEEE Trans. Geosci. Remote Sensing 1997, 35(3), 747-755.

19. Fensholt, R.; Sandholt, I.; Stisen, S. Evaluating MODIS, MERIS, and VEGETATION Vegetation indices using in situ measurements in a semiarid environment. IEEE Trans. Geosci. Remote Sensing 2006, 44(7), 1774-1786.

20. Jung, M.; Henkel, K.; Herold, M.; Churkina, G. Exploiting synergies of global land cover products for carbon cycle modeling. Remote Sens. Environ. 2006, 101(4), 534-553.

21. Brown, M.E.; Pinzon, J.E.; Didan, K.; Morisette, J.T.; Tucker, C.J. Evaluation of the consistency of long-term NDVI time series derived from AVHRR, SPOT-Vegetation, SeaWiFS, MODIS, and Landsat ETM+ sensors. IEEE Trans. Geosci. Remote Sensing 2006, 44(7), 1787-1793.

22. Curren, P.J.; Hay, A.M. The importance of measurement error for certain procedures in remote sensing at optical wavelength. Photogramm Eng Rem S 1986, 52, 229-241.

23. Iwasaki, A.; Fujisada, H. ASTER geometric performance. IEEE Trans. Geosci. Remote Sensing 2005, 43(12), 2700-2706.

24. Fujisada, H.; Bailey, G.B.; Kelly, G.G.; Hara, S.; Abrams, M.J. ASTER DEM performance. IEEE Trans. Geosci. Remote Sensing 2005, 43(12), 2707-2714.

25. Wolfe, R.E.; Nishihama, M.; Fleig, A.J.; Kuyper, J.A.; Roy, D.P.; Storey, J.C.; Patt, F.S. Achieving sub-pixel geolocation accuracy in support of MODIS land science. Remote Sens. Environ. 2002, 83(1-2), 31-49.

26. Running, S.W.; Justice, C.O.; Salomonson, V.; Hall, D.; Barker, J.; Kaufmann, Y.J.; Strahler, A.H.; Huete, A.R.; Muller, J.P.; Vanderbilt, V.; Wan, Z.M.; Teillet, P.; Carneggie, D. Terrestrial remote sensing science and algorithms planned for EOS/MODIS. Int. J. Remote Sensing 1994, 15(17), 3587-3620.

27. Miura, T.; Huete, A.R.; Ferreira, L.G.; Sano, E.E.; Yoshioka, H. A technique for reflectance calibration of airborne hyperspectral spectrometer data using a broad, multi-band radiometer. In: Kalacska M, editor. Hyperspectral Remote Sensing of Tropical and Sub-tropical Forests: CRS Press (in press).

28. Thome, K.; Palluconi, F.; Takashima, T.; Masuda, K. Atmospheric correction of ASTER. IEEE Trans. Geosci. Remote Sensing 1998, 36(4), 1199-1211.

29. Vermote, E.; Saleous, N. Operational Atmospheric Correction of MODIS Visible to Middle Infrared Land Surface Data in the Case of an Infinite Lambertian Target. Earth Science Satellite Remote Sensing; 2006. p 123-153.

30. Vermote, E.F.; ElSaleous, N.; Justice, C.O.; Kaufman, Y.J.; Privette, J.L.; Remer, L.; Roger, J.C.; Tanre, D. Atmospheric correction of visible to middle-infrared EOS-MODIS data over land surfaces: Background, operational algorithm and validation. J Geophys Res-Atmos 1997, 102(D14), 17131-17141.

31. Barbieri, R.; Montgomery, H.; Qiu, S.; Barnes, B.; Knowles, D., Jr. ; Che, N.; Goldberg, I.L. The MODIS Level 1B Algorithm Theoretical Basis Document Version 2.0 (ATBD-MOD-01): NASA Goddard Space Flight Center, Greenbelt, MD; 1997. 68 p. 
32. Herman, B.M.; Browning, S.R. A numerical solution to the equation of radiative transfer. $J$. Atmos. Sci. 1965, 22(5), 559-566.

33. Vermote, E.F.; Tanre, D.; Deuze, J.L.; Herman, M.; Morcrette, J.J. Second Simulation of the Satellite Signal in the Solar Spectrum, 6S: An overview. IEEE Trans. Geosci. Remote Sensing 1997, 35(3), 675-686.

34. Gao, B.; Kaufman, Y.J. Water vapor retrievals using Moderate Resolution Imaging Spectroradiometer (MODIS) near-infrared channels. J. Geophys. Res. 2003, 108(D13), 4389, doi:10.1029/2002JD003023.

35. Tucker, C.J. Red and photographic infrared linear combinations for monitoring vegetation. Remote Sens. Environ. 1979, 8, 127-150.

36. Huete, A.; Didan, K.; Miura, T.; Rodriguez, E.P.; Gao, X.; Ferreira, L.G. Overview of the radiometric and biophysical performance of the MODIS vegetation indices. Remote Sens. Environ. 2002, 83(1-2), 195-213.

37. Miura, T.; Huete, A.R.; Yoshioka, H.; Holben, B.N. An error and sensitivity analysis of atmospheric resistant vegetation indices derived from dark target-based atmospheric correction. Remote Sens. Environ. 2001, 78(3), 284-298.

38. Huete, A.; Didan, K.; van Leeuwen, W.; Miura, T.; Glenn, E. MODIS Vegetation Indices. Land Remote Sensing and Global Environmental Change: NASA's Earth Observing System and the Science of ASTER and MODIS. (in press); 2008.

39. Holben, B.N.; Tanré, D.; Smirnov, A.; Eck, T.F.; Slutsker, I.; Abuhassan, N.; Newcomb, W.W.; Schafer, J.S.; Chatenet, B.; Lavenu, F.; Kaufman, Y.J.; Vande Castle, J.; Setzer, A.; Markham, B.; Clark, D.; Frouin, R.; Halthore, R.; Karneli, A.; O'Neill, N.T.; Pietras, C.; Pinker, R.T.; Voss, V.; Zibordi, G. An emerging ground-based aerosol climatology: Aerosol Optical Depth from AERONET. J. Geophys. Res. 2001, 106, 12,067-12,097.

(C) 2008 by MDPI (http://www.mdpi.org). Reproduction is permitted for noncommercial purposes. 